\title{
Photophysics, Molecular Reorientation in Solution and X-Ray Structure of a New Fluorescent Probe, 1,7-Diazaperylene
}

\author{
Lennart B-Å. Johansson* and Jan Karolin \\ Department of Physical Chemistry, University of Umeå, S-901 87 Umeå, Sweden \\ Heinz Langhals, Susanne Reichherzer, Nicolai von Füner and Kurt Polborn \\ Department of Organic Chemistry, University of Munich, Karlstrasse 23, D-8000 Munich 2, Germany
}

\begin{abstract}
A new fluorescent molecule 1,7-diazaperylene (DP) has been investigated by means of time-resolved and steady-state polarized fluorescence spectroscopy, as well as $X$-ray spectroscopy. Absorption and fluorescence spectra of DP in solution are similar to those of perylene. However, absorption and fluorescence spectra of 2,8dimethoxy DP and 2,8-dipentyloxy DP in solution are red-shifted by ca. $55 \mathrm{~nm}$ relative to perylene. The fluorescence decay of DP is exponential with a lifetime of $5.1 \mathrm{~ns}$ in ethanol, $4.9 \mathrm{~ns}$ in glycerol and $4.3 \mathrm{~ns}$ in paraffin oil. The radiative lifetime in ethanol was calculated to be $6.3 \mathrm{~ns}$ for DP, $8.0 \mathrm{~ns}$ for 2,8-dimethoxy DP and $7.6 \mathrm{~ns}$ for 2,8-dipentyloxy DP. The calculated fluorescence quantum yields of 0.8 for DP and its alkoxy derivatives in ethanol, are in good agreement with those obtained from measurements. The calculated Förster radius is $37.2 \pm 1 \AA$ for DP and $41.9 \pm 1 \AA$ for its alkoxy derivatives in ethanol. Examining the $S_{0} \leftrightarrow S_{1}$ transition, we obtain a limiting fluorescence anisotropy of $r_{0} \approx 0.38$ for DP and its alkoxy derivatives. The rotational rates of DP in paraffin oil and glycerol were compared to that of perylene. In paraffin oil both molecules show an almost identical biexponential decay of the fluorescence anisotropy, which is compatible with a rotational motion like an oblate ellipsoid. The fluorescence anisotropy is monoexponential for DP in glycerol, and DP appears to rotate like a spherical particle while perylene in glycerol appears to rotate like an oblate ellipsoid. Moreover, the rotational diffusion constant, corresponding to rotation about an axis in the aromatic plane $\left(D_{1}\right)$, is the same for both DP and perylene in glycerol.
\end{abstract}

Perylene and its derivatives are of interest in various applications and are topics of research as, for example, chemically and light-stable pigments, ${ }^{1}$ laser dyes, ${ }^{2-4}$ fluorescent solar antennas, ${ }^{5}$ fluorescence immunoassays, ${ }^{6}$ reporter molecules in membrane research, ${ }^{7,8}$ probe molecules in membranes ${ }^{9}$ as well as in the modelling of electronic energy transfer in lipid bilayers. ${ }^{10}$

In this article we report on fluorescence spectroscopic studies of 2 new derivative of perylene, 1,7-diazaperylene (DP; benz[de]isoquinolino[1,8-gh]quinoline) and two of its derivatives, 2,8-dimethoxy-1,7-diazaperylene and 2,8dipentyloxy-1,7-diazaperylene. The fluorescence lifetime and quantum yield were determined by means of time-resolved and steady-state fluorescence spectroscopy. From the fluorescence anisotropy of DP in glycerol and paraffin oil we analyse the rotational motions which we compare to results previously obtained for perylene. ${ }^{11,12}$

The DP molecule has about the same molecular mass as perylene (see Fig. 1) but, owing to the $\mathrm{sp}^{2}$ hybridization of two nitrogens, these can form hydrogen bonds with protic solvents. Furthermore, the aromatic plane of perylene is probably not planar because of steric repulsion between the hydrogen atoms bound to C-atoms 1 and 12, as well as 6 and (a)

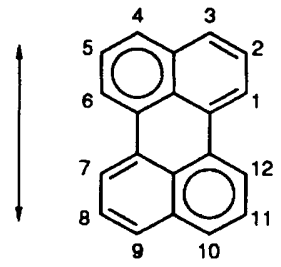

(b)

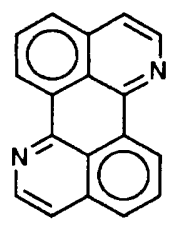

Fig. 1 Structure formulae of perylene $(a)$ and 1,7-diazaperylene (b). The arrow indicates the transition dipole moment of the electronic $S_{0} \leftrightarrow S_{1}$ transition of perylene
7. Recently, Zannoni and co-workers ${ }^{13}$ reported that the two naphthalene rings of perylene are mutually tilted at an angle of $c a .11^{\circ}$. This steric hindrance is eliminated in DP. Hence DP is expected to be a 'planar perylene'.

\section{Experimental}

1,7-Diazaperylene and 2,8-dimethoxy-1,7-diazaperylene were synthesized as described in ref. 14.

\section{2,8-Dipentyloxy-1,7-diazaperylene}

2,8-Dihydroxy-1,7-diazaperylene disodium salt $^{14}(1 \mathrm{~g} ; 3$ mmol) was dissolved in DMF $(100 \mathrm{ml})$ and after addition of potassium carbonate $(2.5 \mathrm{~g})$ and 1-bromopentane $(1.7 \mathrm{ml} ; 10$ mmol) heated to $445 \mathrm{~K}$ for $3 \mathrm{~h}$ and then quenched by the addition of ice water $(150 \mathrm{ml})$ and filtered $(0.8 \mathrm{~g})$. The raw material was purified twice by column separation with toluene and silica gel and then recrystallized from toluene. Yield $0.15 \mathrm{~g}(12 \%)$ orange crystals, m.p. $430-431 \mathrm{~K} ; r_{\mathrm{f}}$ (silica gel $/$ toluene $)=0.84 ;$ IR $(\mathrm{KBr}): v / \mathrm{cm}^{-1}=3070(\mathrm{w}), 2945(\mathrm{~m})$, $2927(\mathrm{~m}), 2870(\mathrm{~m}), 1604(\mathrm{~s}), 1581(\mathrm{~s}), 1464(\mathrm{w}), 1446(\mathrm{~m}), 1431$ (m), $1399(\mathrm{~m}), 1344(\mathrm{~m}), 1319(\mathrm{~s}), 1280(\mathrm{~m}), 1227(\mathrm{~m}), 1151(\mathrm{~s})$, $1109(\mathrm{~s}), 1072(\mathrm{~m}), 843(\mathrm{~m}), 692(\mathrm{~m}) . \mathrm{UV}$ (toluene): $\lambda_{\max } / \mathrm{nm}$ $\left[\log \left(\varepsilon / 1 \mathrm{~mol}^{-1} \mathrm{~cm}^{-1}\right)\right]=437 \mathrm{~nm}(3.979), 465(4.348), 488 \mathrm{sh}$, 496 (4.501); UV $\left(\mathrm{CHCl}_{3}\right): \lambda_{\max } / \mathrm{nm} \quad\left[\log \left(\varepsilon / 1 \mathrm{~mol}^{-1}\right.\right.$ $\left.\left.\mathrm{cm}^{-1}\right)\right]=430 \mathrm{~nm} \mathrm{sh}, 459(4.297), 488(4.411) . \mathrm{MS}(70 \mathrm{eV}): \mathrm{m} / z$ $(\%)=428(4.6), 427(31.5), 426\left[\mathrm{M}^{+}\right](100), 383(4.3), 370(5.1)$, 369 (16.2), 35\% (6.4), 356 (16.9), 327 (3.3), 313 (1.9), $300(3), 299$ (8.9), 287 (6.8), 286 (27.8), $269(4.8), 259$ (3), 258 (15.9), 257 (5.7), 241 (4.5), 230 (7.4), 224 (7.3), 203 (3.5), 91 (2.4), 43 (2.2). $\mathrm{C}_{28} \mathrm{H}_{30} \mathrm{~N}_{2} \mathrm{O}_{2}$ (426.5), calc. C, 78.84\%; H, $7.09 \%$;, $6.57 \%$; found $\mathrm{C}, 78.85 \% ; \mathrm{H}, 7.03 \% ; \mathrm{N}, 6.46 \%$. 


\section{Crystal Structures $\dagger$}

Diffractometer: ENRAF-Nonius CAD4, radiation: Mo-K $\alpha$ Monochromator: Highly oriented graphite crystal.

\section{1,7-Diazaperylene}

$\mathrm{C}_{18} \mathrm{H}_{10} \mathrm{~N}_{2}, M_{\mathrm{r}}=254.3, a=8.020$ (2) $\AA ; b=6.378$ (2) $\AA$; $c=12.206$ (3) $\AA ; \beta-107.70(2)^{\circ} ;$ volume $594.8 \AA^{3} ; Z=2$, density $($ calc. $)=1.420 \mathrm{Mg} \mathrm{m}^{-3}, \mu=0.79 \mathrm{~cm}^{-1}$, crystal system monoclinic, space group $P 2_{1} / c$ (no. 14). Data collection: single crystal: $0.2 \times 0.33 \times 0.4 \mathrm{~mm}^{3}, \omega-2 \theta$ scan, measured $2 \theta$ range: $4.0-44.0^{\circ}$ in $h k \pm l$, signal width $1.00^{\circ} \pm 0.35 \tan \theta$, background measurement: stationary counter at beginning and end of scan, each for $25.0 \%$ of total scan time. Standard reflexions: three measured every 100 reflexions, index ranges $-8 \leqslant h \leqslant 8,0 \leqslant k \leqslant 6,0 \leqslant l \leqslant 12$; 774 reflexions collected, 676 independent reflexions $\left(R_{\text {int }}=\right.$ $2.77 \%), 592$ considered as observed $[I \geqslant 2 \sigma(I)]$. No absorption correction. Solution of structure: direct methods, anisotropic description of the non-hydrogen atoms, isotropic description of the $\mathrm{H}$-atoms, 91 parameters, $R=0.0752, R_{\mathrm{w}}=$ $0.0689, w^{-1}=F+0.0 F^{2}$, residue of max. and min. electron density $\left(10^{6} \mathrm{e} \mathrm{pm}^{-3}\right) 0.20-0.24$; a model with $\mathrm{N}$ on the position of $\mathrm{C}(6)$ can be excluded $\left(R=0.1068, R_{\mathrm{w}}=0.0979\right)$. Further data are given in Table 1.

\section{2,8-Dipentyloxy-1,7-diazaperylene}

$\mathrm{C}_{28} \mathrm{H}_{30} \mathrm{~N}_{2} \mathrm{O}_{2}$ (orange plate), $M_{\mathrm{r}}=426.6, a=10.894$ (2) $\AA$; $b=5.005 \quad$ (1) $\AA ; c=21.430 \quad$ (4) $\AA ; \beta=104.48 \quad(2)^{\circ}$; volume $=1131.3 \AA^{3} ; Z=2$, density (calc.) $=1.252 \mathrm{Mg} \mathrm{m}^{-3}$, $\mu=0.73 \mathrm{~cm}^{-1}$, crystal system monoclinic, space group $P 2_{1} / n$ (no. 14). Data collection: single crystal: $0.13 \times 0.53 \times 0.6$ $\mathrm{mm}^{3}, \omega-2 \theta$ scan, measured $2 \theta$ range: $4.0-46.0^{\circ}$ in $\pm h k l$, signal width $0.90^{\circ}+0.35 \tan \theta$, background measurement: stationary counter at beginning and end of scan, each for $25.0 \%$ of total scan time. Standard reflexions: three measured every 100 reflexions, index ranges $0 \leqslant h \leqslant 8,0 \leqslant k \leqslant 4$, $-22 \leqslant l \leqslant 22 ; 1886$ reflexions collected, 1522 independent reflexions $\left(\boldsymbol{R}_{\mathrm{int}}=2.77 \%\right), 1352$ considered as observed $[I \geqslant 2 \sigma(I)]$. No absorption correction. Solution of structure: direct methods, anisotropic description of the non-hydrogen atoms, isotropic description of the $\mathrm{H}$-atoms, 145 parameters, $R=0.0530, R_{\mathrm{w}}=0.0449, w^{-1}=\mathrm{F}+0.0 F^{2}$, residue of $\max$. and min. electron density $\left(10^{6} \mathrm{e} \mathrm{pm}^{-3}\right) 0.15-0.21$. $\omega$-gemini delta $\omega=0.29^{\circ}$

Table 1 Atomic coordinates $\left(\times 10^{4}\right)$ of 1,7-diazaperylene

\begin{tabular}{lclcl}
\hline atom & $x$ & $y$ & $z$ & $U(\mathrm{eq})$ \\
\hline $\mathrm{N}(1)$ & $3357(5)$ & $1251(7)$ & $1235(3)$ & $66(2)$ \\
$\mathrm{C}(1)$ & $3569(8)$ & $2992(10)$ & $1897(5)$ & $76(3)$ \\
$\mathrm{C}(2)$ & $2238(9)$ & $4224(9)$ & $1977(4)$ & $74(3)$ \\
$\mathrm{C}(3)$ & $502(7)$ & $3688(8)$ & $1350(4)$ & $56(2)$ \\
$\mathrm{C}(4)$ & $-973(10)$ & $4858(9)$ & $1405(5)$ & $75(3)$ \\
$\mathrm{C}(5)$ & $-2589(9)$ & $4156(10)$ & $818(5)$ & $77(3)$ \\
$\mathrm{C}(6)$ & $-2877(7)$ & $2368(8)$ & $159(4)$ & $58(2)$ \\
$\mathrm{C}(7)$ & $-1496(6)$ & $1185(7)$ & $63(4)$ & $46(2)$ \\
$\mathrm{C}(8)$ & $237(6)$ & $1852(7)$ & $677(3)$ & $44(2)$ \\
$\mathrm{C}(9)$ & $1737(6)$ & $679(7)$ & $632(4)$ & $47(2)$ \\
$\mathrm{H}(1 \mathrm{~A})$ & 4738 & 3377 & 2337 & 80 \\
$\mathrm{H}(2 \mathrm{~A})$ & 2473 & 5450 & 2456 & 80 \\
$\mathrm{H}(4 \mathrm{~A})$ & -828 & 6124 & 1849 & 80 \\
$\mathrm{H}(5 \mathrm{~A})$ & -3584 & 4945 & 865 & 80 \\
$\mathrm{H}(6 \mathrm{~A})$ & -4054 & 1941 & -239 & 80 \\
\hline
\end{tabular}

† Atomic coordinates, bond lengths and angles and thermal parameters have been deposited at the Cambridge Crystallographic Data Centre; further information available from the Editorial office.
Table 2 Atomic coordinates $\left(\times 10^{4}\right)$ of 2,8-dipentyloxy-1,7-diazaperylene

\begin{tabular}{|c|c|c|c|c|}
\hline $\mathbf{N}(1)$ & $230(2)$ & $2380(5)$ & $3897(1)$ & $58(1)$ \\
\hline$O(1)$ & $-435(2)$ & $1715(4)$ & $2800(1)$ & $72(1)$ \\
\hline $\mathrm{C}(1)$ & $86(3)$ & $3678(6)$ & 4419 (1) & $52(1)$ \\
\hline $\mathrm{C}(2)$ & $-841(2)$ & $5640(6)$ & $4401(1)$ & $50(1)$ \\
\hline$C(3)$ & $-957(2)$ & $6998(6)$ & 4962 (1) & 52 (1) \\
\hline C(4) & $-1867(3)$ & $8942(6)$ & $4909(1)$ & $65(1)$ \\
\hline$C(5)$ & $-2688(3)$ & $9556(6)$ & $4307(1)$ & 70 (1) \\
\hline $\mathrm{C}(6)$ & $-2604(3)$ & $8247(6)$ & 3768 (1) & $66(1)$ \\
\hline$C(7)$ & $-1684(3)$ & $6238(6)$ & $3792(1)$ & $56(1)$ \\
\hline $\mathrm{C}(8)$ & $-1532(3)$ & $4829(6)$ & 3257 (1) & $63(1)$ \\
\hline C(9) & $-576(3)$ & $2995(6)$ & $3336(1)$ & $61(1)$ \\
\hline $\mathrm{C}(10)$ & $548(3)$ & $-246(6)$ & $2878(1)$ & $71(1)$ \\
\hline$C(11)$ & $495(3)$ & $-1386(6)$ & $2223(1)$ & $75(1)$ \\
\hline $\mathrm{C}(12)$ & $982(3)$ & $496(7)$ & $1790(1)$ & 77 (1) \\
\hline$C(13)$ & 929 (3) & $-615(7)$ & $1133(2)$ & $97(2)$ \\
\hline$C(14)$ & $1448(4)$ & $1182(8)$ & $716(1)$ & $115(2)$ \\
\hline $\mathrm{H}(4 \mathrm{~A})$ & -1942 & 9893 & 5287 & 80 \\
\hline$H(5 A)$ & -3316 & 10926 & 4279 & 80 \\
\hline$H(6 A)$ & -3179 & 8685 & 3363 & 80 \\
\hline $\mathrm{H}(8 \mathrm{~A})$ & -2089 & 5143 & 2840 & 80 \\
\hline $\mathbf{H}(10 \mathrm{~A})$ & 422 & -1629 & 3166 & 80 \\
\hline $\mathrm{H}(10 \mathrm{~B})$ & 1360 & 563 & 3053 & 80 \\
\hline$H(11 A)$ & -370 & -1831 & 2020 & 80 \\
\hline $\mathrm{H}(11 \mathrm{~B})$ & 981 & -3006 & 2271 & 80 \\
\hline $\mathrm{H}(12 \mathrm{~A})$ & 1846 & 942 & 1994 & 80 \\
\hline $\mathrm{H}(12 \mathrm{~B})$ & 495 & 2115 & 1743 & 80 \\
\hline $\mathrm{H}(13 \mathrm{~A})$ & 61 & -1000 & 923 & 80 \\
\hline $\mathrm{H}(13 \mathrm{~B})$ & 1388 & -2270 & 1181 & 80 \\
\hline $\mathrm{H}(14 \mathrm{~A})$ & 1379 & 341 & 306 & 80 \\
\hline $\mathrm{H}(14 \mathrm{~B})$ & 981 & 2828 & 655 & 80 \\
\hline $\mathrm{H}(14 \mathrm{C})$ & 2324 & 1543 & 916 & 80 \\
\hline
\end{tabular}

\section{Time-resolved Fluorescence Measurements}

A PRA 3000 system (Photophysical Research Ass. Inc., Canada) was used for single-photon-counting measurements of the fluorescence decay. The excitation source was a thyratron-gated flash lamp (Model 510C, PRA) filled with deuterium gas and operated at $c a .30 \mathrm{kHz}$. The excitation wavelengths were selected by interference filters (Omega/ Saven AB, Sweden) centred at $409.4 \mathrm{~nm}(\mathrm{HBW}=13.0 \mathrm{~nm})$ and $497.1 \mathrm{~nm}(\mathrm{HBW}=31 \mathrm{~nm})$. The fluorescence emission was observed above 470 and $550 \mathrm{~nm}$ through long-pass filters Schott KV 470 and KV 550 (Schott, West Germany), respectively. The maximum absorbance of all samples was kept below 0.08 .

The time-resolved polarized fluorescence decay curves were measured by repeated collection of photons during $200 \mathrm{~s}$, for each setting of the polarizers. The emission polarizer was fixed and the excitation polarizer rotated periodically. In each experiment the decay curves $F_{\|}(t)$ and $F_{\perp}(t)$ were collected. The suffices $\|$ and $\perp$ refer to an orientation of the emission polarizer parallel and perpendicular with respect to the excitation polarizer. From these a sum curve

$$
S(t)=F_{\|}(t)+2 G F_{\perp}(t)
$$

and a difference curve

$$
D(t)=F_{\|}(t)-G F_{\perp}(t)
$$

were calculated. The correction factor, $G$, was obtained by normalizing the total number of counts $F_{\|}$and $F_{\perp}$ collected in $F_{\|}(t)$ and $F_{\perp}(t)$, respectively, to the steady-state anisotropy, $r_{\mathrm{s}}$, as

$$
G=\left(1-r_{\mathrm{S}}\right)\left(1+2 r_{\mathrm{S}}\right) F_{\|}\left(F_{\perp}\right)^{-1}
$$

The data were analysed with a MINC-11/03 computer using the deconvolution software (DECAY V3.0a, ATROPY V1.0) developed by PRA. 


\section{Fluorescence Quantum Yield, $\Phi$}

Perylene in ethanol and fluorescein in $0.1 \mathrm{~mol} \mathrm{dm}^{-3} \mathrm{NaOH}$ were used as reference standards with reported quantum yields of $0.92^{15-17}$ and $0.93,{ }^{18}$ respectively. The quantum yield to be determined, $\Phi_{\text {sample }}$, was calculated from

$$
\Phi_{\text {sample }}=\Phi_{\text {ref }} \frac{F_{\text {ref }}}{F_{\text {sample }}} \frac{1-\exp \left(-A_{\text {ref }} \ln 10\right)}{1-\exp \left(-A_{\text {sample }} \ln 10\right)} \frac{n_{\text {sample }}^{2}}{n_{\text {ref }}^{2}}
$$

where, $F$ denotes the integral of the corrected fluorescence spectrum, $A$ is the absorbance at the excitation wavelength and $n$ is the refractive index.

\section{Radiative Lifetime, $\tau_{0}$}

The corrected fluorescence $F(v)$, of the chromophore dissolved in ethanol was determined at $298 \mathrm{~K}$. Here $v$ stands for the wavenumber. The molar absorptivity as a function of wavenumber, $\varepsilon(v)$, was determined from the absorption spectrum recorded on the chromophore solution. From $\varepsilon(v), F(v)$ and the modified Strickler-Berg equation ${ }^{19}$

$$
\frac{1}{\tau_{0}}=2.88 \times 10^{-9} n^{2} \frac{\int F(v) \mathrm{d} v}{\int F(v) v^{-3} \mathrm{~d} v} \int \varepsilon(v) v^{-1} \mathrm{~d} v
$$

the radiative lifetime $\tau_{0}$ is obtained. Since the fluorescence lifetime is known from the time-resolved fluorescence decay, the quantum yield is obtained from $\tau=\phi \tau_{0}$. The value of $\phi$ is compared with that determined independently as described above.

\section{Förster Radius}

The Förster radius as, defined by Kawski, ${ }^{20}$ is

$$
R_{\mathrm{OF}}=\left|\frac{900(\ln 10)\left\langle\kappa^{2}\right\rangle \phi J}{128 \pi^{5} n^{4} N_{\mathrm{A}}}\right|^{1 / 6}
$$

where

$$
J=\int \varepsilon(v) f(v) v^{-4} \mathrm{~d} v
$$

and

$$
f(v)=\frac{F(v)}{\int F(v) \mathrm{d} v}
$$

where $N_{\mathrm{A}}$ and $n$ denote the Avogadro constant and the refractive index of the medium. $\left\langle\kappa^{2}\right\rangle$ is a mean value of the orientational part of a dipole-dipole interaction. In order to calculate an explicit value on the Förster radius it is convenient to choose $\left\langle\kappa^{2}\right\rangle=2 / 3$ as reference state which corresponds to the mean value for an interaction between rapidly rotating dipoles in a three-dimensional system. This case is often referred to the dynamic limit or the fast case. We denote this Förster radius by $R_{0}$. For ethanol $n=1.36$.

\section{Results and Discussion}

\section{Geometry by Crystal Structure Analysis}

The geometry of 1,7-diazaperylene has been examined by crystal structure analysis. 1,7-Diazaperylene crystallizes in two or more modifications. The reported ${ }^{14}$ yellow needles have a melting point of $529-530 \mathrm{~K}$ and correspond to a metastable modification. Owing to lattice displacements a crystal structure analysis of this modification could not be obtained. However, recrystallization from toluene-acetone
(4:1) yields a more stable modification. This modification has a melting point of $537-538 \mathrm{~K}$, an orange colour and it forms crystals suitable for structure analysis. The structure of 1,7-diazaperylene is given in Fig. 2(a). The structure of aromatic systems may be appreciably deformed by lattice forces. ${ }^{21}$ In order to exclude that the planarity of 1,7-diazaperylene is just a consequence of these forces, the crystal structure of the derivative 2,8-dipentyloxy-1,7-diazaperylene was additionally determined and displayed in Fig. 2(b). Both structures confirm the planarity of the aromatic heterocycle.

\section{Spectral and Photophysical Properties}

Fig. 3 shows the absorption and fluorescence (corrected) spectra of 1,7-diazaperylene (DP) and 2,8-dimethoxy-1,7-diazaperylene in ethanol. The spectral shapes are similar to that of perylene with its characteristic vibronic structure. However, absorption and fluorescence spectra of DP and its alkoxy derivatives are red-shifted relative to those of perylene by 8 and $55 \mathrm{~nm}$, respectively. The molar absorptivities of the $0-0^{\prime}$ vibronic peak are $28100 \pm 2001 \mathrm{~mol}^{-1} \mathrm{~cm}^{-1}$ for DP, $29500 \pm 2001 \mathrm{~mol}^{-1} \mathrm{~cm}^{-1}$ and $30350 \pm 2001 \mathrm{~mol}^{-1} \mathrm{~cm}^{-1}$ for 2,8-dimethoxy DP and 2,8-dipentyloxy DP, respectively, which are to be compared with the corresponding value of $372701 \mathrm{~mol}^{-1} \mathrm{~cm}^{-1}$ for perylene in ethanol. By using the absorption and fluorescence spectra as well as the modified Strickler-Berg equation we calculate the radiative lifetimes $\left(\tau_{0}\right)$ to be $6.3 \mathrm{~ns}$ for DP, $8.0 \mathrm{~ns}$ for 2,8-dimethoxy DP and 7.6 ns for 2,8-dipentyloxy DP. Time-resolved fluorescence experiments yield monoexponential decays of the photophysics with a lifetime of $\tau=5.1 \mathrm{~ns}$ for DP and $6.2 \mathrm{~ns}$ for the derivatives in ethanol at $298 \mathrm{~K}$. Since the fluorescence quantum yield is given by $\Phi=\tau / \tau_{0}$ we calculate that $\Phi(D P)=\Phi(2,8-$ dipentyloxy $\mathrm{DP})=0.81$ and $\Phi(2,8$-dimethoxy $\mathrm{DP})=0.78$. Independent measurements of the quantum yield of fluorescence give $\Phi(\mathrm{DP})=0.83 \pm 0.05$ and $\Phi($ alkoxy-DP) $=0.80 \pm 0.05$. Note that the samples were not degassed.

The fluorescence lifetime of DP in glycerol and paraffin oil is monoexponential, 4.9 and $4.6 \mathrm{~ns}$, respectively, and independent of temperature in the range $260-305 \mathrm{~K}$ as investigated in this work.

The Förster radii of DP and the dialkoxy derivatives of DP in ethanol were found to be $37.2 \pm 1$ and $41.9 \pm 1 \AA$, respectively. These values are greater than $33.6 \pm 0.2 \AA$ reported for 2,5,8,11-tetra-tert-butylperylene (TBPe, see ref. 10 and papers cited therein). The greater $R_{0}$ values of DP and the dialkoxy derivatives, as compared to that of TBPe, are mainly due to their more efficient overlap between absorption and fluorescence spectra.

\section{Fluorescence Anisotropy}

In order to obtain information about the polarization of the electronic transition dipoles of the $S_{0} \leftrightarrow S_{1}$ transition, we examined the fluorescence excitation and emission anisotropies at low temperatures, where rotational motions of the fluorophores can be neglected. Both excitation and emission anisotropies are constant with excitation and emission wavelengths, respectively, which shows that the band corresponds to one direction of the electronic transition dipole moment. The steady-state anisotropy of DP and alkoxy-DP in glycerol approaches a constant value below $c a$. $260 \mathrm{~K}$. This means that indeed the influence of rotational motions is negligible, and that the value of the limiting fluorescence anisotropy, $r_{0}$, is reached. The obtained values of $r_{0}$ are $0.375 \pm 0.005$ for DP and $0.382 \pm 0.005$ for its derivatives. These values of $r_{0}$ are somewhat larger than those found for perylene and its alkyl derivatives, ${ }^{21}$ but they are still significantly smaller than 


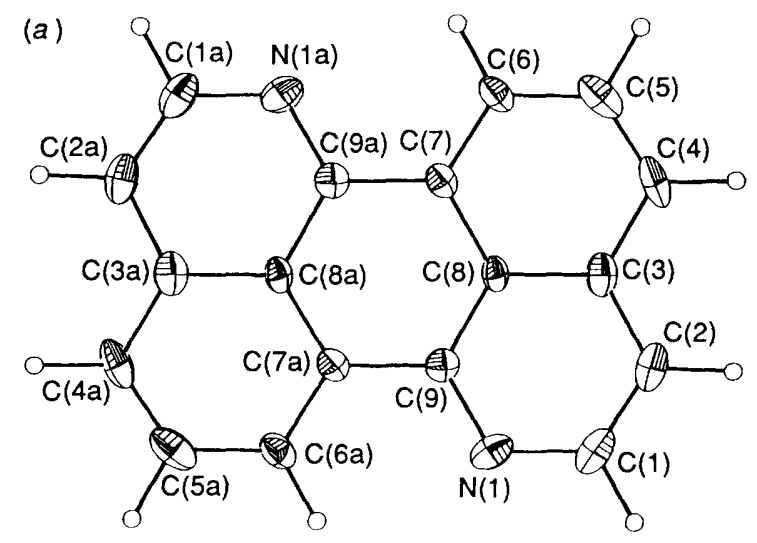

(b)

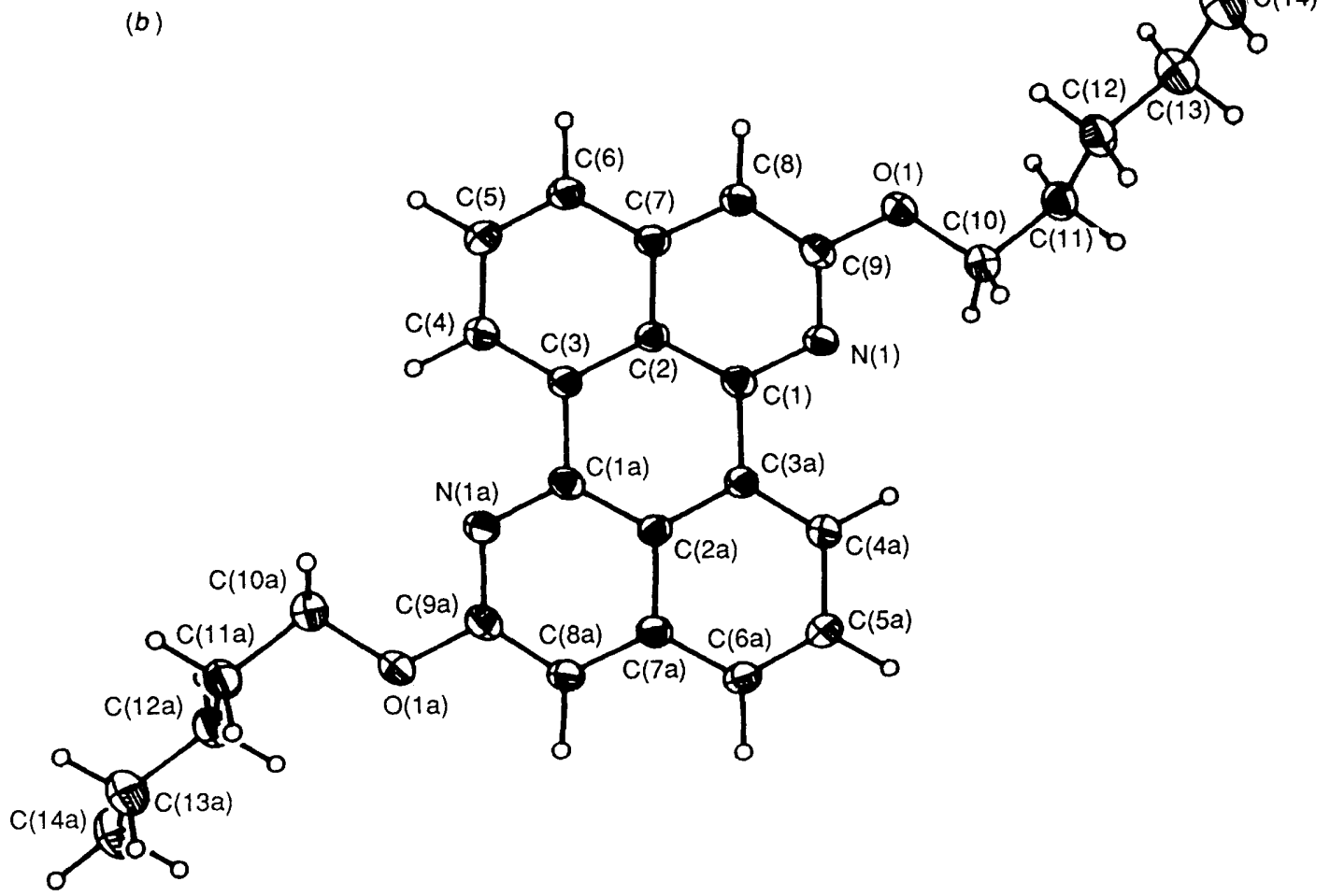

Fig. 2 Structures of 1,7-diazaperylene (a) and 2,8-dipentyloxy-1,7-diazaperylene $(b)$. The structure is similar to the one of perylene, but the ring system is planar. The molecules are packed in the herringbone structure which is typical for polycyclic aromatic hydrocarbons

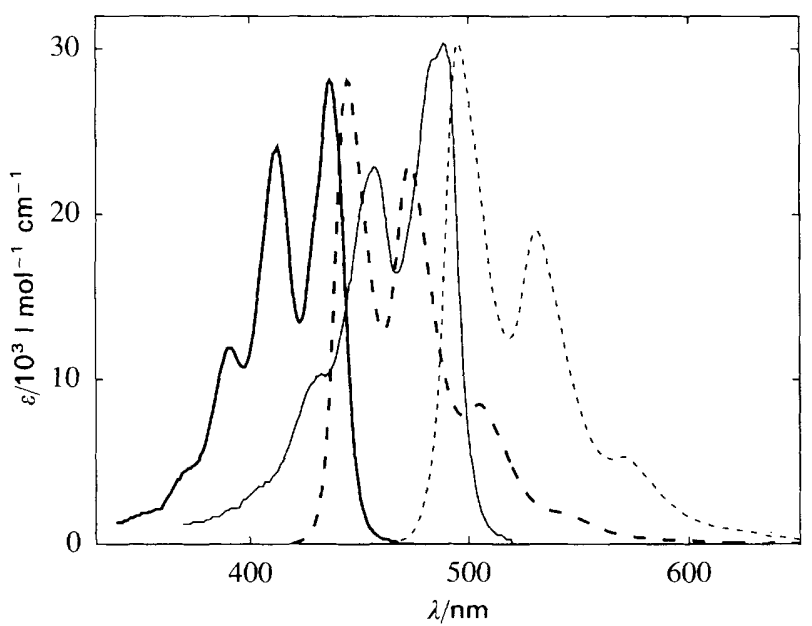

Fig. 3 Absorption ( - ) and fluorescence (-- ) (corrected) spectra of 1,7-diazaperylene (bold lines) and 2,8-dipentyloxy-1,7-diazaperylene (feint lines) in ethanol the theoretical value of $2 / 5$, expected for parallel absorption and emission dipoles. Since the DP chromophore is planar, as shown by X-ray spectroscopy, the deviation between the observed and theoretical values of $r_{0}$ cannot be ascribed to the non-planarity of the perylene molecule in its ground state. However, the deviations between $r_{0}$ and $2 / 5$ found for DP can still be due to a distortion of the excited-state geometry.

The rotational motion of DP in paraffin oil and glycerol has been studied by means of time-resolved fluorescence anisotropy. The viscosity of paraffin oil followed the relation ${ }^{1}$

$$
\eta=\eta_{0} \exp \left(\Delta E_{\eta} / R T\right)
$$

with $\Delta E_{\eta}=45.3 \mathrm{~kJ} \mathrm{~mol}^{-1}$ and $\eta_{0}=1.26 \mathrm{cP}$. The steady-state anisotropies of DP and perylene in paraffin oil are very similar at different temperatures (data not shown). This indicates that both molecules rotate in much the same way which is also supported by the time-resolved fluorescence anisotropy $[r(t)]$. The decay of $r(t)$ fits nicely to a sum of two exponential functions, as expected if the molecules undergo 
rotational diffusion like an oblate ellipsoid, that is ${ }^{22,23}$

$$
\begin{aligned}
r(t) & =a_{1} \exp \left(-t / \phi_{1}\right)+a_{2} \exp \left(-t / \phi_{2}\right) \\
\phi_{1} & =\left(6 D_{\perp}\right)^{-1} \\
\phi_{2} & =\left(2 D_{\perp}+4 D_{\|}\right)^{-1}
\end{aligned}
$$

In eqn. (1b) and (1c) $D$ denotes the diffusion coefficient for rotation about ( $\perp$ ) and perpendicular ( $\|)$ to the $C_{\infty}$ symmetry axis of an oblate molecule. For mutually parallel absorption and emission dipoles polarized perpendicular to the $C_{\infty}$ axis, $a_{1}=0.1$ and $a_{2}=0.3$. The pre-exponential factor $a_{1}$ is insensitive to librational motions about the $C_{\infty}$ axis while such motions, as well as a small inherent angle between the absorption and emission dipoles, will effectively decrease $a_{2}$ so that, for example, $a_{2} \approx 0.26$ for an angle of $5^{\circ}$ (see ref. 12).

We find that $r(t)$ for DP, as well as for perylene in paraffin oil can be analysed with eqn. (1a) for essentially the same values of $a_{1} \approx 0.1$ and $a_{2}<0.3$. As can be seen from Fig. 4 , the rotational correlation times $\phi_{1}$ and $\phi_{2}$ are very similar for DP and perylene. Consequently, the rotational diffusion coefficients, calculated from eqn. $(1 b)$ and $(1 c)$, also become very similar. The ratio of $D_{\|} / D_{\perp} \approx 10$ is essentially the same as that previously obtained for perylene in propylene glycol $^{24}$ as well as glycerol. ${ }^{11}$ Zinsli interpreted this result as indicating boundary conditions between slipping and sticking. ${ }^{25}$

Let us proceed to the anisotropy data obtained for DP in glycerol, and compare these data with those of perylene. The steady-state anisotropy of DP as a function of temperature is significantly larger than that of perylene, which strongly suggests a slower rotational relaxation of DP (data not shown). Moreover, $r(t)$ of DP is a monoexponential function in contrast to perylene, where $r(t)$ is biexponential. For DP the preexponential factor is $c a .0 .38$ at all temperatures studied, i.e. between 264 and $303 \mathrm{~K}$. This is compatible with a diffusion coefficient of $D_{\|} \approx D_{\perp}=D$ in eqn. (1), yielding

$$
\begin{aligned}
r(t) & =r_{0} \exp (-t / \phi) \\
\phi & =(6 D)^{-1}
\end{aligned}
$$

and it means that the rotational motion of DP in glycerol resembles that of a spherical particle. Comparison with the data on perylene in glycerol ${ }^{11}$ demonstrates that the diffusion coefficient of the diazaperylene is equal to $D_{\perp}$ of perylene, within the accuracy of the experiment. This is illustrated in Fig. 5. Thus, the rotational rate about an axis in the aromatic

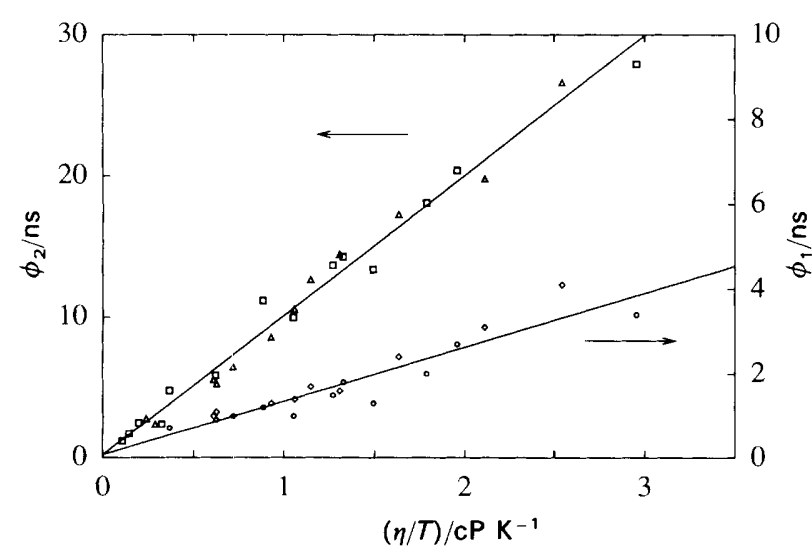

Fig. 4 Rotational correlation times $\left(\phi_{1}\right.$ and $\left.\phi_{2}\right)$ of 1,7-diazaperylene $\left(\phi_{1}, \square ; \phi_{2}, \bigcirc\right)$ and perylene $\left(\phi_{1}, \Delta ; \phi_{2}, \diamond\right)$ in paraffin oil as a function of the ratio between solvent viscosity ( $\eta$ in $\mathrm{cP}$ ) and temperature

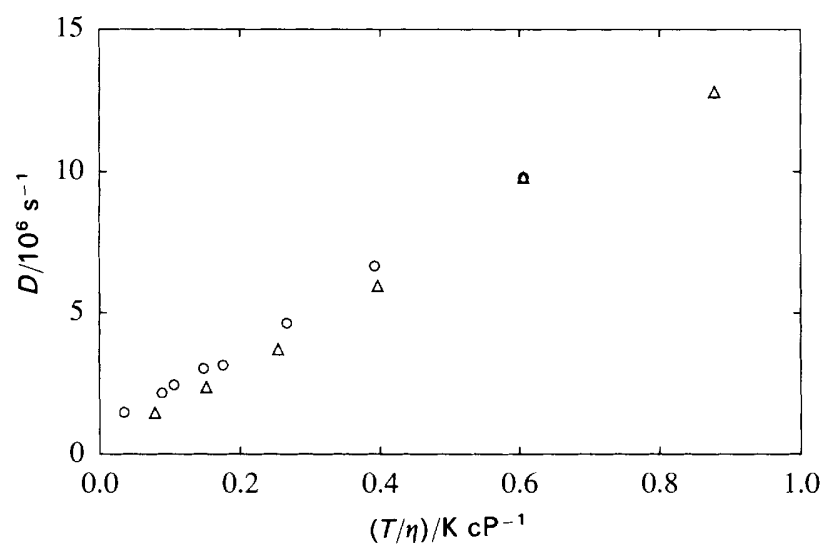

Fig. 5 Rotational diffusion coefficient $(D)$ of 1,7-diazaperylene $(O)$ and perylene $(\triangle)$ in glycerol as a function of the ratio between temperature and solvent viscosity ( $\eta$ in $\mathrm{cP}$ ). For perylene $D=D_{1}$, that is, the rotational diffusion perpendicular to the assumed $C_{\infty}$ axis. Data on the viscosity of glycerol were taken from ref. 26

plane of DP and perylene are equal. This could also be expected, since the size and mass of DP is nearly equal to that of perylene, suggesting that such a rotation involves the same energy of displacing the same number of solvent molecules. However, the reason that $D_{\|} \approx D_{\perp}$ for DP must be ascribed to hydrogen bonding between the nitrogens of DP and the $\mathrm{OH}$ groups of glycerol. Because of these bonds, the solvent will stick to DP and hamper the rotational rate about the $C_{\infty}$ axis. Furthermore, the finding of nearly identical rotational motions of DP and perylene in paraffin oil, where no hydrogen bonds can be formed, supports this explanation.

This work was supported by the Swedish Natural Research Council, Deutsche Forschungsgemeinschaft and Fonds der Chemischen Industrie.

\section{References}

$1 \mathrm{~W}$. Herbst and K. Hunger, Industrielle Organische Pigmente, VCH, Weinheim, 1987, vol. 1 .

2 H-G. Löhmannsröben and H. Langhals, Appl. Phys. B, 1989, 48, 449.

3 E. M. Ebeid, S. A. El-Daly and H. Langhals, J. Phys. Chem., $1988,92,4565$.

4 M. Sadrai and G. R. Bird, Opt. Commun., 1984, 51, 62.

5 H. Langhals, Nachr. Chem. Tech. Lab., 1980, 28, 716; Chem. Abs., 1981, 95, R9816q.

6 H. Langhals, H. Schott and R. A. Schwendener, D.O.S., 3935257.9, 1989.

7 C. Zannoni, A. Arcioni and P. Cavatorta, Chem. Phys. Lipids, $1983,32,179$.

8 L. B-A. Johansson, J. G. Molotkovsky and L. D. Bergelson, J. Am. Chem. Soc., 1987, 109, 7374.

9 L. D. Bergelson, J. G. Molotkovsky and Y. M. Manevich, Chem. Phys. Lipids, 1985, 37, 165.

10 B. Kalman and L. B-Å. Johansson, J. Phys. Chem., 1992, 96, 185.

11 M. D. Barkley, A. A. Kowalczyk and L. Brand, J. Chem. Phys., $1981,75,3581$

12 B. Kalman, N. Clarke and L. B-Å. Johansson, J. Phys. Chem., $1989,93,4608$.

13 G. N. Shilstone, C. Zannoni and C. A. Verachini, Liq. Cryst., $1989,6,303$

14 C. Naumann and H. Langhals, Chem. Ber., 1990, 123, 1881.

15 W. H. Melhuish, J. Phys. Chem., 1960, 64, 762.

16 J. N. Demas and G. A. Crosby, J. Phys. Chem., 1961, 65, 229.

17 W. Dawson and M. W. Winsor, J. Phys. Chem., 1968, 72, 3251.

18 G. Weber and F. W. J. Teale, Trans. Faraday Soc., 1958, 54, 640

19 J. B. Birks, Photophysics of Aromatic Molecules, WileyInterscience, New York, 1970.

20 A. Kawski, Photochem. Photobiol., 1983, 38, 487. 
21 J. B-Å. Johansson, J. Chem. Soc., Faraday Trans., 1990, 86, 2103.

22 T-I. Chuang and K. B. Eisenthal, J. Chem. Phys., 1972, 57, 5074

23 M. Ehrenberg and R. Rigler, Chem. Phys. Lett., 1972, 14, 539

24 M. Shinitzky, S. C. Dianoux, C. Gitler and G. Weber, Biochemistry, 1971, 10, 2106

25 P. E. Zinsli, Chem. Phys., 1977, 20, 299.
26 J. B. Segur, Glycerol, ACS Monograph Series, ed. C. S. Miner and N. N. Dalton, American Chemical Society, Washington D.C., 1953 .

Paper 2/04104I; Received 30th July, 1992 